\title{
Age of initiation, Determinants and Prevalence of Cigarette Smoking among Teenagers in Mushin Local Government Area of Lagos State, Nigeria
}

\author{
AO Abiola ${ }^{1}$, OS Balogun ${ }^{2 *}$, OO Odukoya ${ }^{1}$, FA Olatona ${ }^{1}$, TO Odugbemi ${ }^{1}$, RK \\ Moronkola $^{3}$, AA Solanke ${ }^{4}$, OJ Akintunde ${ }^{5}$, OO Fatoba ${ }^{1}$
}

\begin{abstract}
Background: Cigarette smoking constitutes a major threat to the health and wellbeing of teenagers. While smoking has been on decline in the developed countries, the reverse is the case in developing countries. The aim of this study was to determine the age of initiation, determinants and prevalence of cigarette smoking among teenagers in Mushin Local Government Area of Lagos state, Nigeria. Materials and Methods: This was a descriptive cross-sectional study among 475 teenagers selected by multistage sampling. A pre-tested, structured, interviewer-administered questionnaire was used for data collection. The study was carried out in November, 2014. Results: Response rate was $84.6 \%$. Mean age of the respondents was 16.4+1.65years. Range and mean age

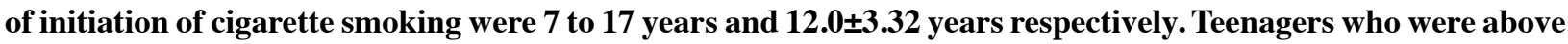
15 years (OR:5.13, 95\% CI: 0.87-30.26), males (OR:5.19, 95\% CI: 1.57-17.18), married (OR:8.41, 95\% CI: 1.0463.35), had $\leq$ primary school education(OR:4.31,95\% CI: 1.07-17.33), influenced by friends(OR:308.84,95\% CI: 84.87-1123.81), and influenced by advertisements (OR:27.83, 95\% CI: 3.92-197.64) were more likely to have initiated cigarette smoking. Furthermore, teenagers who were males (OR:12.77, 95\% CI: 2.90-56.28), married (OR:19.24, 95\% CI: 2.05-180.45), had sprimary school education(OR:7.85, 95\% CI: 2.37-26.01), influenced by friends(OR:28.56,95\% CI: 10.86-75.07), and influenced by advertisements (OR:5.95, 95\% CI: 1.72-20.61) were more likely to be current cigarette smokers. In addition, $24.9 \%$ had initiated cigarette smoking while $14.7 \%$ were current smokers of cigarette. Conclusions: Mean age of initiation of cigarette smoking was 12.0 \pm 3.32 years. Determinants of cigarette smoking were age, gender, marital status, educational background, friends and advertisements. Life time prevalence of cigarette smoking was higher than prevalence of current cigarette smokers. Cigarette smoking reduction programs should take these factors into consideration.
\end{abstract}

Keywords: Age of initiation - determinants of cigarette smoking - teenagers - prevalence - Nigeria

Asian Pac J Cancer Prev, 17 (3), 1209-1214

\section{Introduction}

Tobacco smoking remains a major public health concern particularly among young people (Odukoya et al., 2013). It is the leading preventable cause of mortality and over five million people die globally from the effects of tobacco every year. Every eight seconds someone, somewhere in the world, dies as a result of using tobacco (Leung et al., 2009). It is reported that by the year 2030, the death rate is estimated to exceed eight million people a year Global Youth Tobacco Survey Collaborative Group (GYTS, 2002).

According to the World Health Organization (WHO) it is estimated that 1.1 billion people, representing a third of the world population above the age of 15 years, use tobacco, principally in the form of the cigarettes and of these, 700 million of them being males live in developing countries. While smoking rates have been on the decline in the developed countries, they have however been on the high side in the developing countries and it has increased by as much as $50 \%$, especially in Asia and in the Pacific region. Over the last decade about four million deaths occurred annually as a result of about $50 \%$ increase in rate of smoking cigarette in developing countries.

In Europe, an estimate of $26 \%$ of people aged 15 years and above approximately 100 million people smoke on a daily basis (AIHW, 2008). China and Indian, the two world's most populous nations are home to more smokers than the entire European Union. In China alone, more than 300 million people are tobacco users while in India about 275 million people use tobacco and about 57 million Indonesians are tobacco smokers (David, 2012). However

${ }^{l}$ Department of Community Health and Primary Care, College of Medicine, University of Lagos, ${ }^{2}$ Lagos State Ministry of Education, ${ }^{3}$ Department of Internal Medicine, Lagos University Teaching Hospital, ${ }^{4}$ Multichoice Nigeria Limited, ${ }^{5}$ Phamatex Industries Limited, Lagos State, Nigeria *For correspondence: seunballo2004@yahoo.co.uk 


\section{AO Abiola et al}

in Africa, the prevalence of smoking varies from country to country. In South Africa, 33.3\% of males and $8.2 \%$ of females smoke. In Kenya, $22.9 \%$ of males smoke and $0.7 \%$ of females smoke. In Ghana, $8.8 \%$ of males and $0.1 \%$ of females smoke. Comparatively, in Nigeria, $8.0 \%$ of males and $0.5 \%$ of females smoke (Pampel, 2008).

Smoking of tobacco appears to be a well-entrenched behaviour among teenagers. Adolescence period is seen as a forming stage, a resistant period where young people tries to form their own identity and also try to belong to a particular stratified social group. Initiation of smoking at a tender age is a behaviour that occurs at a time when the persons involved are not fully equipped to make certain decisions and these decisions may affect their inclination to addiction and also influences adult smoking behavior. Epidemiological study suggest that most tobacco users begin as adolescents and individuals who reach their mid-20s as nonsmokers are unlikely to ever become tobacco users (Aldrich et al., 2015). It is estimated that
$80 \%$ of adult regular smokers initiate tobacco use before the age of 18 (Poynter, 2008). However, initiation of tobacco in teenagers is usually due to interaction of different factors which include intrapersonal, interpersonal and environmental factors. Some intrapersonal factors associated with adolescent smoking include lower levels of knowledge on hazards of smoking (Yan et al., 2014), low self-esteem (Karimy et al 2013; Nazarzdeh et al., 2013). Peer pressure and having friends who smoke has been considered as the most important factor influencing the habit of smoking in adolescents in the western world; (Schaefer et al., 2012), also motivation by smoking behavior of parents and siblings, the media, secondhand smoke exposure, curiosity, and a drive for experimentation (Voorhes et al., 2011).

The earlier a smoker quits smoking the less the hazard, as evidence suggests that much of the projected mortality from smoking can be prevented by stopping. This study seeks to determine the age of initiation, determinants

Table 1. Factors Associated with Initiation of Cigarette Smoking among Teenagers, Mushin LGA,

\begin{tabular}{|c|c|c|c|}
\hline \multicolumn{4}{|c|}{ Initiation of cigarette smoking } \\
\hline \multirow[t]{2}{*}{ Variables } & \multicolumn{2}{|c|}{ Frequency $(\%)$} & \multirow[t]{2}{*}{ Statistics \& Pvalue } \\
\hline & Initiated & Never initiated & \\
\hline \multicolumn{4}{|l|}{ Age (Years) } \\
\hline$\leq 15$ & $84(31.1)$ & $186(68.9)$ & \multirow{4}{*}{$\mathrm{t}=5.0315 ; \mathrm{df}=400 ; \mathrm{p}=0.0001$} \\
\hline$>15$ & $16(12.1)$ & $116(87.9)$ & \\
\hline Total & $100(24.9)$ & $302(75.1)$ & \\
\hline Mean \pm SD & $17.07 \pm 1.53$ & $16.14 \pm 1.63$ & \\
\hline \multicolumn{4}{|l|}{ Gender } \\
\hline Male & $87(34.1)$ & $168(65.9)$ & \multirow{2}{*}{$\mathrm{X}^{2}=31.8734 ; \mathrm{df}=1 ; \mathrm{p}=0.0001$} \\
\hline Female & $13(8.8)$ & $134(91.2)$ & \\
\hline \multicolumn{4}{|l|}{ Marital Status } \\
\hline Unmarried & $95(24.1)$ & $299(75.9)$ & \multirow{2}{*}{$* \mathrm{p}=0.0255$} \\
\hline Married & $5(62.5)$ & $3(37.5)$ & \\
\hline \multicolumn{4}{|l|}{ Religion } \\
\hline Christian & $45(21.1)$ & $168(78.9)$ & \multirow{2}{*}{$* \mathrm{p}=0.0418$} \\
\hline Islam & $55(29.1)$ & $132(70.9)$ & \\
\hline \multicolumn{4}{|l|}{ Ethnic group } \\
\hline Yoruba & $81(26.7)$ & $222(73.3)$ & \multirow{2}{*}{$* \mathrm{p}=0.0831$} \\
\hline Others (Hausa/Fulani/ Igbo) & $19(19.2)$ & $80(80.8)$ & \\
\hline \multicolumn{4}{|l|}{ Educational Background } \\
\hline$\leq$ Primary School & $21(48.8)$ & $22(51.2)$ & \multirow{2}{*}{$* \mathrm{p}=0.0003$} \\
\hline$\geq$ Secondary School & $79(22.0)$ & $280(78.0)$ & \\
\hline \multicolumn{4}{|l|}{ Friends influence } \\
\hline Yes & $83(94.3)$ & $5(5.7)$ & \multirow{2}{*}{$* \mathrm{p}=0.0001$} \\
\hline No & $17(5.4)$ & $297(94.6)$ & \\
\hline \multicolumn{4}{|l|}{ Advert influence } \\
\hline Yes & 29 (90.6) & $3(9.4)$ & \multirow{2}{*}{$* \mathrm{p}=0.0001$} \\
\hline No & $71(19.2)$ & $299(80.8)$ & \\
\hline \multicolumn{4}{|l|}{ Parents influence } \\
\hline Yes & $12(85.7)$ & 2 (14.3) & \multirow{2}{*}{$* \mathrm{p}=0.0001$} \\
\hline No & $88(22.7)$ & $200(77.3)$ & \\
\hline \multicolumn{4}{|l|}{ Relatives influence } \\
\hline Yes & $26(87.7)$ & 3 (10.3) & \multirow{2}{*}{$* \mathrm{p}=0.0001$} \\
\hline No & $74(19.8)$ & $299(80.2)$ & \\
\hline
\end{tabular}

*Fisher's Exact tests 
and prevalence of cigarette smoking among teenagers in Mushin Local Government Area of Lagos state, Nigeria.

\section{Materials and Methods}

\section{Study location}

Mushin local government area (LGA) in the Lagos metropolis is one of the 20 LGAs in Lagos state, Nigeria. It is one of the major commercial centres in Lagos state. The 2006 census put the population of the LGA at 631,857 , with 326,873 males and 304,984 females. Mushin LGA has 19 political wards. Each ward in Mushin LGA had an average of 40 streets and each street had about 36 houses, each house had an average of ten households, and each household consist of an average of five persons. The Local Government is a socio-cultural diversity of the typical Nigerian society because it is well represented by various ethnic groups.

\section{Study design}

The study design was a descriptive cross-sectional study among teenagers that were permanent residents in Mushin LGA. The confidence interval and degree of accuracy desired were set at $95 \%$ and $5 \%$ respectively. The minimum sample size of 250 was determined using the formula $\mathrm{n}=\mathrm{Z} 2 \mathrm{pq} / \mathrm{d} 2$ for descriptive cross-sectional study with the prevalence of tobacco use amongst adolescents in a previous study carried out in Kajola LGA, Oyo state, Nigeria of 0.205 .13 However, 475 respondents were selected for the study. Respondents were selected by multi-stage sampling method. In the first stage, one street was selected from each ward by simple random sampling method using balloting procedure. In the second stage, five houses were selected from each selected street by simple random sampling method using balloting procedure. In the third stage, five households were selected from each selected house by simple random sampling method using balloting procedure. In the fourth stage, one teenager was selected from each selected household by simple random sampling method using balloting procedure. Where a household has no teenager, another household is selected to replace it. This study was carried out in November, 2014.

\section{Data collection}

A pre-tested structured interviewer-administered questionnaire was used to collect information on sociodemographic characteristics and tobacco cigarette smoking among teenagers. The questionnaire was adapted from previous studies and from the World Health Organization Global Youth Tobacco Survey tool (CDC, 2008). The questionnaire comprises of two sections: Section A had 6 questions on socio-demographic characteristics, section B had 14 questions on tobacco cigarette smoking.

\section{Data analysis}

Data analysis was done using the Epi Info version 3.5.1, GraphPad Instat and WinPepi statistical software packages. Chi-square and Fisher exact tests were used to compare differences between proportions while t-test was used for comparison of differences between means. $\mathrm{P}$ values of $\leq 0.05$ were considered statistically significant. Logistic regression analyses were carried out to determine factors associated with tobacco cigarette smoking. For the multivariate analyses, all the variables that were statistically significant on the bivariate were entered into the multivariate analyses.

Ethical consideration: Approval for this study was obtained from the ethics and research committee of the Lagos University Teaching Hospital. Verbal informed consent was obtained from each respondent.

\section{Results}

A total of 402 out of the 475 selected respondents participated in the study; giving a response rate of $84.6 \%$. Mean age of the respondents was $16.37 \pm 1.65$ years. Majority of the respondents were males (63.4\%), unmarried (95\%), Christians (53\%), Yoruba by tribe $(75.4 \%)$ and had minimum of secondary school education $(89.3 \%)$ (Table 1$)$.

Less than one-third (24.9\%) of the respondents had ever smoked tobacco cigarette while $14.7 \%$ were current cigarette smokers. The modal and mean age of initiation of cigarette smoking was 15years and $12.00 \pm 3.32$ years respectively (Table2). Reasons for smoking initiation were primarily friends $(21.9 \%)$, advertisements $(8.0 \%)$, relatives $(7.2 \%)$ and parents $(3.5 \%)$. Sixty six (16.4\%) of the respondents like to smoke with friends, $10 \%$ like to smoke always, $9.0 \%$ like to smoke when nervous, $6.7 \%$ like to smoke when idle while $5.0 \%$ like to smoke when over-worked.

A bivariate analysis showed that there were statistically significant associations between the respondents' age $(\mathrm{p}=0.0001)$, gender $(\mathrm{p}=0.0001)$, marital status $(\mathrm{p}=0.0255)$, religion $(\mathrm{p}=0.0418)$, educational background $(\mathrm{p}=0.0001)$, friends $(\mathrm{p}=0.0001)$, advert $(\mathrm{p}=0.0001)$, parent $(\mathrm{p}=0.0001)$, relatives $(\mathrm{p}=0.0001)$ and initiation cigarette smoking (Table 1). There were statistically significant

Table 2. Age of Initiation of Cigarette Smoking among Teenagers, Mushin LGA, Lagos state, Nigeria, 2014

\begin{tabular}{cc}
\hline $\begin{array}{c}\text { Age of initiation of cigarette } \\
\text { smoking (Years) }\end{array}$ & $\begin{array}{c}\text { Frequency }(\%) \\
(\mathrm{n}=100)\end{array}$ \\
\hline 7 & $1(1.0)$ \\
8 & $2(2.0)$ \\
9 & $4(4.0)$ \\
10 & $7(7.0)$ \\
11 & $2(2.0)$ \\
12 & $3(3.0)$ \\
13 & $6(6.0)$ \\
14 & $11(11.0)$ \\
15 & $26(26.0)$ \\
16 & $15(15.0)$ \\
17 & $8(8.0)$ \\
Age not given & $15(15.0)$ \\
Total & $100(100.0)$ \\
Mean \pm SD & $12.00 \pm 3.32$ \\
\hline
\end{tabular}


Table 3. Factors Associated with Current Cigarette Smoking among Teenagers, Mushin LGA, Lagos state, Nigeria, 2014

\begin{tabular}{|c|c|c|c|}
\hline \multirow{3}{*}{ Variables } & \multicolumn{2}{|c|}{ Cigarette smoking } & \multirow{3}{*}{ Statistics \& Pvalue } \\
\hline & \multicolumn{2}{|c|}{ Frequency (\%) } & \\
\hline & Yes $(n=59)$ & No $(n=343)$ & \\
\hline \multicolumn{4}{|l|}{ Age } \\
\hline $10-14$ & $52(19.3)$ & $218(80.7)$ & \multirow{4}{*}{$\mathrm{t}=4.283 ; \mathrm{df}=400 ; \mathrm{p}=0.0001$} \\
\hline $15-19$ & $7(16.2)$ & $125(83.8)$ & \\
\hline Total & $59(14.7)$ & $343(85.3)$ & \\
\hline Mean \pm SD & $17.20 \pm 1.42$ & $16.23 \pm 1.65$ & \\
\hline \multicolumn{4}{|l|}{ Gender } \\
\hline Male & $56(22.0)$ & $199(78.0)$ & \multirow{3}{*}{$X^{2}=29.5471 ; d f=1 ; p=0.0001$} \\
\hline Female & $3(2.0)$ & $144(98.0)$ & \\
\hline Total & $59(14.7)$ & $343(85.3)$ & \\
\hline \multicolumn{4}{|l|}{ Marital status } \\
\hline Unmarried & $54(13.7)$ & $340(86.3)$ & \multirow{2}{*}{${ }^{*} \mathrm{p}=0.0023$} \\
\hline Married & $5(62.5)$ & $3(37.5)$ & \\
\hline \multicolumn{4}{|l|}{ Religion } \\
\hline Christian & $25(11.7)$ & $188(88.3)$ & \multirow{2}{*}{$* \mathrm{p}=0.0519$} \\
\hline Islam & $34(18.0)$ & $155(82.0)$ & \\
\hline \multicolumn{4}{|l|}{ Ethnic group } \\
\hline Yoruba & $45(14.9)$ & $258(85.1)$ & \multirow{2}{*}{${ }^{*} \mathrm{p}=0.5040$} \\
\hline Others (Hausa/Fulani/Igbo) & $14(14.1)$ & $85(85.9)$ & \\
\hline \multicolumn{4}{|l|}{ Educational Background } \\
\hline$\leq$ Primary School & $16(37.2)$ & $27(62.8)$ & \multirow{2}{*}{$*_{\mathrm{p}}=0.0001$} \\
\hline$\geq$ Secondary school & $43(12.0)$ & $316(88.0)$ & \\
\hline \multicolumn{4}{|l|}{ Friends influence } \\
\hline Yes & $49(55.7)$ & $39(44.3)$ & \multirow{2}{*}{${ }^{*} \mathrm{p}=0.0001$} \\
\hline No & $10(3.2)$ & $304(96.8)$ & \\
\hline \multicolumn{4}{|l|}{ Advert influence } \\
\hline Yes & $21(65.6)$ & $11(34.4)$ & \multirow{2}{*}{$* \mathrm{p}=0.0001$} \\
\hline No & $38(10.3)$ & $322(89.7)$ & \\
\hline \multicolumn{4}{|l|}{ Parents influence } \\
\hline Yes & 7 (11.9) & $52(88.1)$ & \multirow{2}{*}{$* \mathrm{p}=0.0016$} \\
\hline No & $7(2.0)$ & $336(98.0)$ & \\
\hline \multicolumn{4}{|l|}{ Relatives influence } \\
\hline Yes & $17(58.6)$ & $12(41.4)$ & \multirow{2}{*}{$* \mathrm{p}=0.0001$} \\
\hline No & $42(11.3)$ & $331(88.7)$ & \\
\hline
\end{tabular}

*Fisher's Exact tests

Table 4. Determinants of Initiation of Cigarette Smoking among Teenagers, Mushin LGA, Lagos state, Nigeria, 2014

\begin{tabular}{lccc}
\hline \multicolumn{1}{c}{ Variables } & OR & CI & P \\
\hline Age (>15 yrs / $\leq 15$ yrs) & 5.13 & $0.87-30.26$ & 0.0709 \\
Gender (Male / Female) & 5.19 & $1.57-17.18$ & 0.007 \\
Marital status (Married/Unmarried) & 8.41 & $1.04-63.35$ & 0.0464 \\
Educational Background & 4.31 & $1.07-17.33$ \\
( $\leq$ Primary Sch / $\geq$ Secondary Sch) & & & 0.0399 \\
Friend (Yes/ No) & 308.84 & $84.87-1123.81$ & 0.0001 \\
Adverts (Yes/ No) & 27.83 & $3.92-197.64$ \\
\hline
\end{tabular}

relationships between respondents' age $(\mathrm{p}=0.0001)$, gender $(\mathrm{p}=0.0001)$, marital status $(\mathrm{p}=0.0023)$, religion $(p=0.0519)$, educational background $(p=0.0001)$, friends $(\mathrm{p}=0.0001)$, advertisements $(\mathrm{p}=0.0001)$, parents $(\mathrm{p}=0.0016)$, relatives $(\mathrm{p}=0.0001)$ and current cigarette smoking (Table 3).

A multivariate analysis revealed that teenagers who were above 15 years, males, married, had $\leq$ primary school education, influenced by friends, and influenced by advertisement are 5.13,5.19, 8.41, 4.31, 308.84, and

1212 Asian Pacific Journal of Cancer Prevention, Vol 17, 2016 
Table 5. Determinants of Current Cigarette Smokers among Teenagers, Mushin LGA, Lagos State, Nigeria

\begin{tabular}{lccc}
\hline \multicolumn{1}{c}{ Variables } & OR & CI & P \\
\hline $\begin{array}{l}\text { Gender (Male / } \\
\text { Female) }\end{array}$ & 12.77 & $2.90-56.28$ & 0.0008 \\
$\begin{array}{l}\text { Marital status } \\
\text { (Married/ }\end{array}$ & 19.24 & $2.05-180.45$ & 0.0096 \\
$\begin{array}{l}\text { Unmarried) } \\
\text { Educational }\end{array}$ & & & \\
$\begin{array}{l}\text { Background } \\
\text { ( } \leq \text { Primary Sch / } \geq\end{array}$ & 7.85 & $2.37-26.01$ & 0.0007 \\
Secondary Sch) & & & \\
$\begin{array}{l}\text { Friend (Yes/ No) } \\
\text { Adverts (Yes/ No) }\end{array}$ & 28.56 & $10.86-75.07$ & 0.0001 \\
\hline & 5.95 & $1.72-20.61$ & 0.0049 \\
\hline
\end{tabular}

27.83 times respectively more likely to have initiated cigarette smoking (Table 4). Furthermore, teenagers who were males, married, had $\leq$ primary school education, influenced by friends, and influenced by advertisement were $12.77,19.24,7.85$,

\section{Discussion}

This study shed some light on the age of initiation, determinants and prevalence of cigarette smoking among teenagers in Mushin LGA of Lagos State, Nigeria. The mean age of initiation of cigarette smoking was $12 \pm 3.32$ years. Teenagers do not just wake up one day and start smoking; the uptake of cigarette is as a result of various factors. The general reasons given for smoking are also similar to those obtained in this study. The predictors include: peer influence, siblings smoking, exposure to advertisements and parental smoking (Das et al., 2011; Voorhes et al., 2011).

From this study, it was shown that peer influence (21.9\%) was the strongest predictor of smoking followed by exposure to advertisements $(8.0 \%)$, and then the smoking status of relatives (7.2\%) and parents (3.5\%). In a Saudi Arabian study, parental influence $(6.2 \%)$ was the major predictor of smoking. Studies show that adolescents with one or both parents who are smokers are associated with initiation of smoking (Ali et al., 2010). However, the reason why friends influence was the major predictor of smoking in this study could be as a result of negligence on the part of the parents and the environment of the study subjects.

Findings from this study showed that $32(8 \%)$ of the respondents that smoke is as a result of exposure to advertisements, this is because glorification of smoking in films has a potential to influence smoking initiation among the youth (Gale et al., 2006). Tobacco packaging itself is among the most prominent and important forms of tobacco advertising and promotion. The tobacco industry exploits all packaging elements, including pack construction, in addition to graphic design and use of colour, to increase the appeal of smoking (Hammond, 2011).

According to this study, it was shown that out of the 402 respondents only 100 (24.9\%) of the respondents had ever smoked cigarette while 59 (14.7\%) currently smoke cigarette. This is higher than the finding of a study carried out in Northeast Nigeria, in which 18 (15.9\%) had ever smoked and $0.3 \%$ are regular smokers who still smoke (Salawu et al., 2009). The disparity in the results could be as a result of the socio-ethnic differences. Furthermore, in this study males accounted for $95 \%$ of current users compared to 5\% amongst females; this findings agrees with other studies in Nigeria where males were more likely to smoke compared with females (Odukoya et al., 2013)

The prevalence of current smokers in this study is $14.7 \%$ which is similar to a study carried out in Kajola Local Government Area, Oyo state, Nigeria where the prevalence of current smokers was $11.6 \%$ (Akindele et al., 2010) but was lower than the corresponding figures reported by Lovato among school children where the mean prevalence of smoking in all age groups was $22.0 \pm 3.37 \%$ and the mean prevalence of smoking among 15-19 years old was 20.3 $\pm 8.30 \%$ (Lovato et al., 2010).

Consistent with findings obtained in similar studies in many parts of Africa, the lifetime prevalence of smoking cigarette in this study (24.8\%) is lower than among adolescents in some countries in Asia, notably Japan (Odukoya et al., 2013).

In conclusion, mean age of initiation of cigarette smoking was $12.00 \pm 3.32$ years. Determinants of cigarette smoking were age, gender, marital status, educational background, friends and advertisements. Life time prevalence of cigarette smoking was higher than prevalence of current cigarette smokers. Cigarette smoking reduction programs should take these factors into consideration.

\section{References}

Akindele OA, Babalola F, Adesola OS, Owoaje ET (2010). Tobacco use amongst out of school adolescents in a Local Government Area in Nigeria. Substance Abuse Treatment, Prevent Policy, 5, 24.

Aldrich MC, Hidalgo B, Widome R, et al (2015). The role of epidemiology in evidence- based policy making: a case study of tobacco use in youth. Ann Epidemiol, 25, 360-5.

Ali IA, Hani T, Ali A (2010). Knowledge, attitude and practice of tobacco smoking by medical students in Riyadh, Saudi Arabia. Ann Thorac Med, 5, 145-148.

Australian Institute of health and Welfare (2008). National drug strategy household survey: detail findings. Drug statistics series no. 22, cat no. PHE 107. Canberra

Centre for Disease Control and Prevention (2008), Available at http://apps.nccd.cdc.gov/gtssdata/ancillary/documentation. aspx?SUID=1\&DOCT $=1$. (Accessed on 27 August 2014).

Das S, Ghosh M, Sarkar M, J et al (2011). Adolescents speak: Why do we smoke? J Trop Pediatr, 57, 476-80.

David T. Smoking in Asia: A looming health epidemic. Asian Scientist (2012). Available at http://www.asianscientist. com/2012/08/features/smoking-in-asia-looming-healthepidemic.2012. (Accessed on August $15^{\text {th }}$ 2014).

Gale J, Fry B, Smith T (2006). Smoking in film in New Zealand: measuring risk exposure. BMC Public Health, 6, 243-6.

Global Youth Tobacco Survey Collaborative Group (2002). Tobacco use among youth: a cross-country comparison. Tobacco Control, 11: 252-270.

Hammond D (2011). Impact of female-oriented cigarette packaging in the United States. Nicotine Tobacco Res, 13, 579-88.

Karimy M, Niknami S, Heidarnia AR, et al (2013). Prevalence 
AO Abiola et al

and determinants of male adolescents' smoking in Iran: an explanation based on the Theory of Planned Behavior. Iran Red Cres Med J, 15, 187-93.

Leung AK, Hon KL, Kong AY (2009). Fighting tobacco smoking: a difficult but not impossible battle. Int J Environmental Res Public Health, 6, 69-83.

Lovato CY, Zeisser C, Campbell HS, et al (2010). Adolescent smoking: effect of school and community characteristics. Am J Prev Med, 39, 507-14.

Masibo RM, Mndeme E, Nsimba SED, et al (2013) An assessment of knowledge, attitudes and practices of psychoactive substance use among secondary school students in Dodoma Municipality, Tanzania. American $J$ Res Commun, 2013, 1, 200-40.

Nazarzdeh M, Bidel Z, Ayuni E, et al (2013). Smoking staus in Iranian male adolescents: a cross sectional study and a meta-analysis. Addict Behav, 38, 2214-8.

Odukoya OO, Odeyemi KO, Oyeyemi AS, et al (2013). Determinants of smoking initiation and susceptibility to future smoking among school-going adolescents in Lagos state, Nigeria. Asian Pac J Cancer Prev, 14, 1747-53.

Pampel F (2008). Tobacco use in sub-Sahara Africa: Estimates from the demographic health surveys. Soc Sci Med, 66, 1772-83.

Poynter M, Bullen C, Whittaker R, Griff M. (2008). 'Under-18 year old callers to New Zealand's quitline', New Zealand Med J, 121, 24-32.

Salawu FK, Danburam A, Desalu KO, et al (2009). Cigarette smoking habits among adolescents in northeast nigeria. mera: African J Respiratory Med, 9, 8-1188.

Schaefer DR, Haas SA, Bishop NJ, (2012). A dynamic model of US adolescents' smoking and friendship networks. Am J Public Health, 102, $12-8$.

Voorhees CC, Ye C, Carter-Pokras O, et al (2011) Peers, tobacco advertising, and secondhand smoke exposure influences smoking initiation in diverse adolescents. Am J Health Promot, 25, 1-11.

World Health Organization (2014). Street children, substance use and health: Monitoring and evaluation of street children project.

Yan Y, Jacques-Tiura AJ, Chen XG (2014). Application of the Protection Motivation Theory in predicting cigarette smoking among adolescents in China. Addic Behav, 39, $181-8$. 